\title{
FERROKINETICS IN NORMAL PERSONS AND IN PATIENTS HAVING VARIOUS ERYTHROPOIETIC DISORDERS ${ }^{1}$
}

\author{
By REX L. HUFF, PAUL J. ELMLINGER, JOSEPH F. GARCIA, JOHN M. ODA, \\ MARION C. COCKRELL, AND JOHN H. LAWRENCE
}

\author{
(From The Donner Laboratory of Medical Physics, University of California, \\ Berkeley, Cal.)
}

(Submitted for publication June 7, 1951 ; accepted September 10, 1951)

It is possible to detect by external means the movement of Iron-59 within the human body. Individuals with certain hematopoietic disorders are thought to have abnormalities in the turnover mechanism of labelled iron. Plasma and red cell turnover of radio iron have been the topic of a previous report (1). A group of patients with various hematologic disorders have been studied by an $\mathrm{Fe}^{58}$ in vivo technique, and although each disease is represented by too few cases to make generalizations, the deviations from normal of iron turnover of liver, spleen, and bone marrow are so remarkable that a report of the methods and findings was thought desirable.

These studies have been made possible by the recent construction of reliable high-efficiency scintillation counters. Detailed descriptions of the construction and performance of these caunting devices have been published by Anger $(2,3)$.

\section{METHODS AND MATERIALS}

\section{Counting equipment}

(a) In vivo counter. Figure 1 illustrates the counting head used for in vivo counting. It employs a thalliumactivated sodium iodide crystal, a $2.5 \mathrm{~cm}$. cube, which lies in contact with the end window of a photomultiplier tube (RCA 5819). The side of the crystal toward the patient was shielded against beta radiation.

A hydraulic lift was used to provide vertical mobility in a horizontal plane within a limited range. An adjustable height stool for the patient added to the range of positioning. The counter output was coupled to the scaler unit, which was of the usual design. The unit also contained the regulated high voltage supply for the photomultiplier tube.

The integrating circuit in connection with a Leeds and Northrup Speedomax recording millivoltmeter comprised a point-plotting linear counting rate recorder with several ranges. The numerous body positions counted and the length of time of the studies required considerable

\footnotetext{
1 This work was supported in part by the Atomic Energy Commission.
}

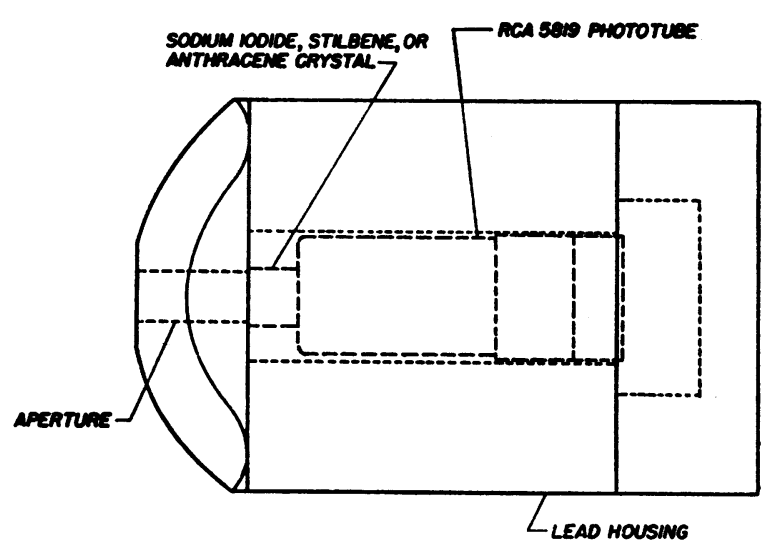

Fig. 1. The Scintillation Counter Head Used in in VIVO Counting

cooperation by the patient and close surveillance by the operator. A mechanized multiple port in vivo counter with simultaneous multichannel recording is now being constructed so that bed patients can be studied and ambulatory patient investigations facilitated.

(b) The vial counter. Figure 2 shows the crystal counter arrangement for receiving the $4 \mathrm{ml}$. screw cap vials (Kimble glass 60910) containing cell or plasma

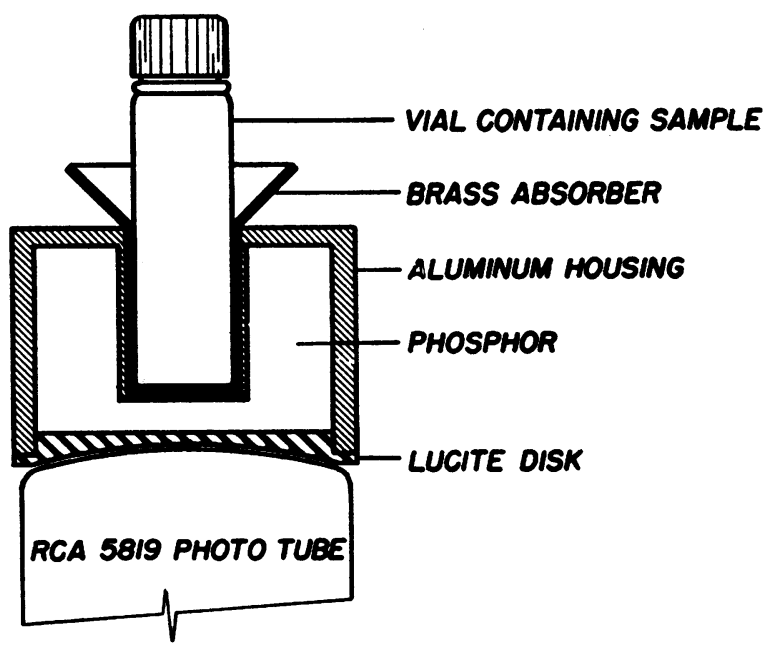

Fig. 2. Crystal-Photo Tube Device for Blood Sample ANALYSIS 
samples. This assembly provided a highly efficient geometry. The operation of the phototube with less than 1 count per minute of the background attributable to phototube "noise" was satisfactory for this work. The tube was operated at less than maximum voltage and cooling or special circuits were not necessary. The shielding consisted of $6 \mathrm{~mm}$. of brass housing, $5 \mathrm{~cm}$. of iron, and $10 \mathrm{~cm}$. of lead.

The overall efficiency of the vial counter is $17.5 \%$ for Iron-59 gammas. This is approximately the efficiency attained with the usual end window G-M tubes for betas of $\mathrm{Fe}^{\infty}$ when electrodeposited samples are analyzed. The saving in time and effort of this method over the old method of analyzing $\mathrm{Fe}^{\mathrm{w}}$ is extraordinary.

The iron isotope was obtained by deuteron bombardment of cobalt in the 60 -inch cyclotron in Berkeley and by a neutron bombardment of enriched $\mathrm{Fe}^{\mathrm{s}}$ from Oak Ridge (4). The cyclotron-produced iron is free of $\mathrm{Fe}^{\mathrm{cs}}$ and only this was used in normal subjects. The most recent cyclotron-bombarded samples have had high specific activity, 10 microcuries per microgram $\mathrm{Fe}$, because of the careful chemistry in preparation of the target and the separation chemistry following the exposure. ${ }^{2}$ The samples from the enriched $\mathrm{Fe}^{*}$ have a slightly lower specific activity and contain small amounts of $\mathrm{Fe}^{\mathrm{ss}}$.

The tracer was kept as a ferric chloride solution. An aliquot of this solution was prepared by reduction with a small amount of thioglycolic acid and neutralization with dilute sodium hydroxide to a $\mathrm{pH}$ of approximately 7 . This mixture was added to an aqueous solution of the Globulin IV-7, Cohn ${ }^{3}$ and was allowed to stand overnight. The iron binding capacity of this protein was measured by a method similar to that used by Surgenor, Koechlin and Strong (5). Usually only about one-half of the available unsaturation was utilized. The mixture was then filtered through a Seitz filter and transferred to sterile serum vials.

The amount of $\mathrm{Fe}^{\star}$ injected varied from 7 to 45 microcuries. Because of radio decay, the total amount of iron and protein given each subject varied considerably; however, in no instance was an amount given which would detectably change the total plasma iron concentration. Thus true tracer amounts of iron were always used.

\section{Injection and blood sampling}

The tracer-globulin solution was injected into the antecubital vein as rapidly as possible. Blood samples were taken at approximately one-fifth, one-half, three-fourths, one and one-half, three, five and 12 hours during the first day. During the ensuing two weeks, from seven to ten samples were taken. The blood was centrifuged at 2,500 r.p.m. for 30 minutes and the packed cell volume recorded. From most of the normal subjects, as well as many of

2 We wish to thank Mr. Rayburn Dunn of the Radiation Laboratory, University of California, for the radiochemistry.

3 The Globulin IV-7 was provided through the generosity of Cutter Laboratories, Berkeley, Cal.

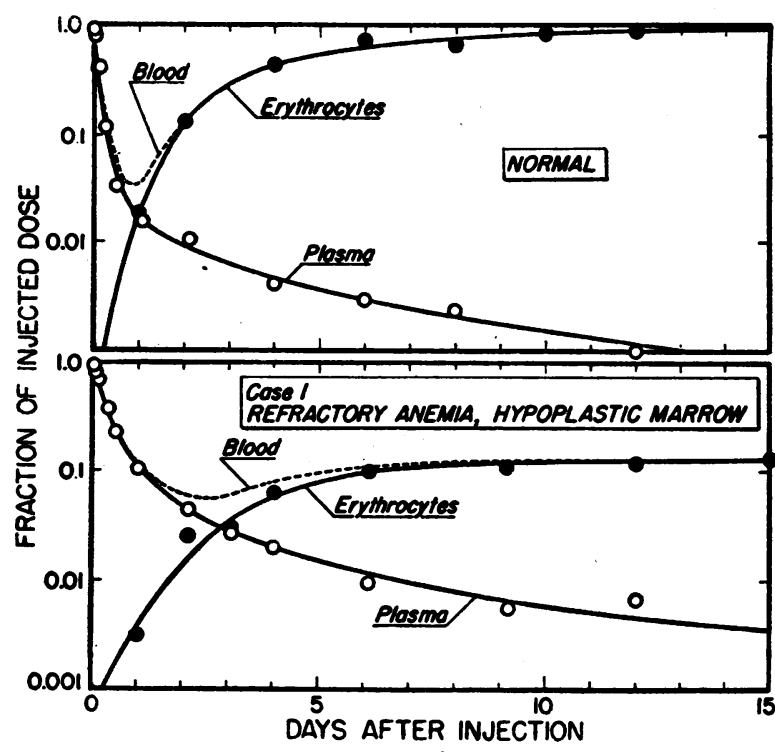

Fig. 3. Fraction of Fe Dose in Plasma Erythrocytes and Blood as a Function of Time after a Single Intravenous InJection

the patients, all specimens from the first four hours were analyzed for total plasma iron by the method of Kitzes, Elvehjem and Schuette (6). No changes in the total iron were noted which would significantly alter the calculated turnover (1). From all blood samples $2 \mathrm{ml}$. of plasma were pipetted to the $4 \mathrm{ml}$. medicine vials for radio analysis in the apparatus shown in Figure 2. The cells from early samples were washed in saline two or three times. After the last washing, an amount of saline equal to the packed cell volume was added to the centrifuge cone. Four ml. of the cell suspension were pipetted to the medicine vials which were then centrifuged, and the $2 \mathrm{ml}$. of cells analyzed in the same manner as the plasma samples.

Plasma radioactivity data were plotted on semilogarithmic paper, and the extrapolated concentration at zero time was used to determine the plasma volume. Total blood volume and red cell volume were computed using this plasma volume and the average hematocrit from the first day's samples. The fraction of $\mathrm{Fe}^{\mathrm{\omega}}$ in red cells, plasma, and blood, calculated from the volumes and concentrations of $\mathrm{Fe}^{\mathrm{s}}$, were plotted as a function of time as illustrated in Figure 3.

\section{Body surface counting rates}

Four principal positions were used in counting tissue volumes thought to be representative of blood, spleen, marrow, and liver. With the subject sitting, the counting aperture was placed against the skin. The precordium was used as the site most likely to reflect changes in a representative volume of blood. A left oblique placement over the costal cartilages with the counter pointed in the direction of the mid-mediastinum was chosen in 

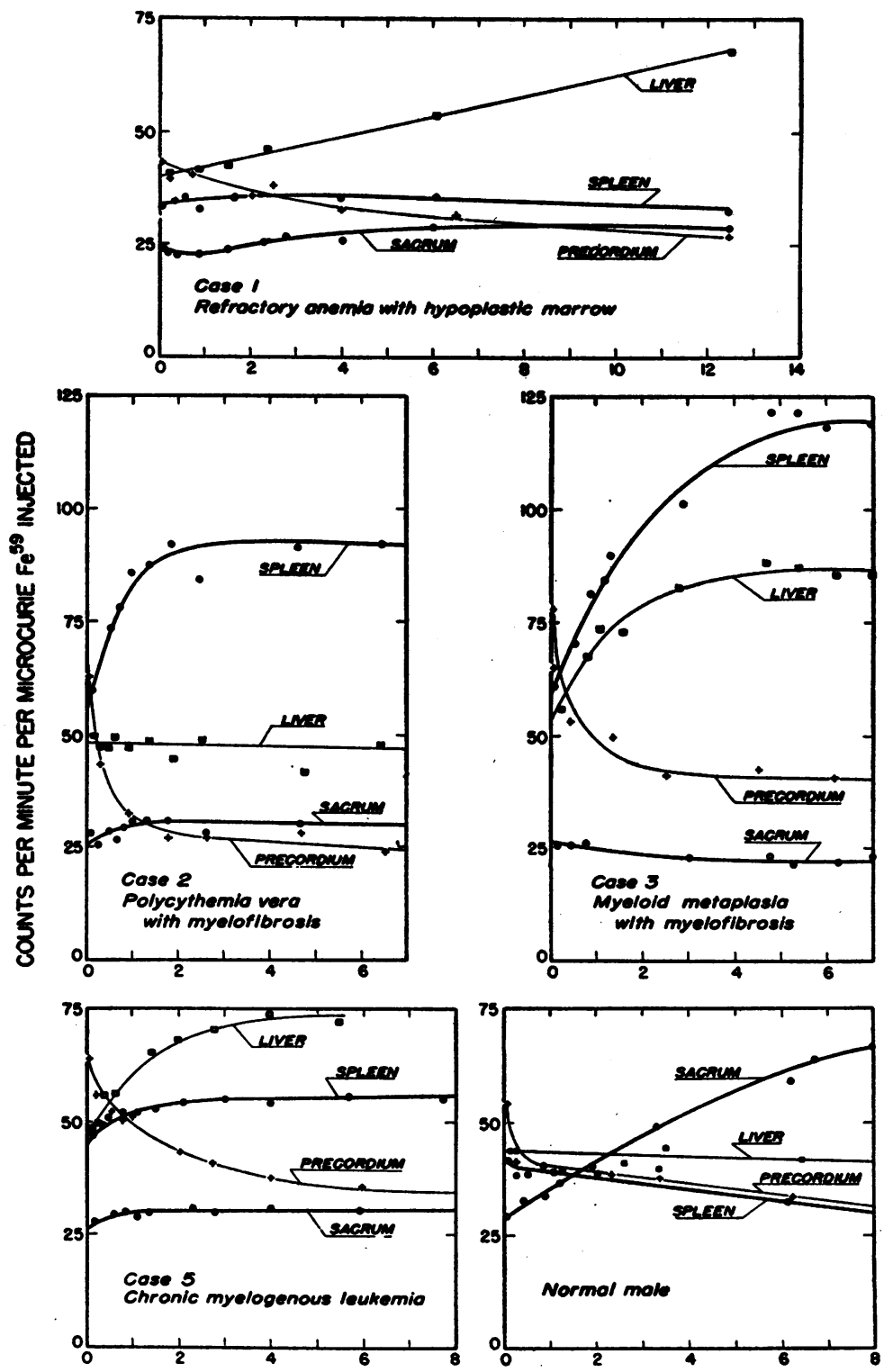

HOURS AFTER INTRAVENOUS INJECTION OF Fe $\mathrm{F}^{59}$

Fig. 4. Gross Body Surface Counting Rates as a Function of Time AFTER a Single Intravenous InJection of FE

order to minimize the contribution of radiation from marrow either in ribs, vertebrae, or sternum.

The right posterior axillary line between the ninth and tenth ribs with minor variations as percussion indicated, was the position used as representative of liver. In this instance, the counter was pointed anteriorly and medially so that the counting axis passed through the anterior midline at the skin surface. An analogous position for a spleen tissue volume was chosen on the left side except when the spleen was palpable. Palpable spleens were counted through the anterior or lateral abdominal wall.

For a site overlying a representative volume of mar- row, the counter was placed over the sacrum and pointed directly anterior, with the patient standing. The extensive and careful investigations of Mechanik (7) as well as the contributions of others concerning the distribution of red bone marrow in the body indicate that the vertebrae and the pelvis contain the major portion' in the adult. The sacrum was estimated by Mechanik to contain approximately $100 \mathrm{gms}$. of hematopoietic marrow, and this, of course, is found in a small volume relatively near the body surface. It was for this reason, as well as the fact that the marrow volume within the cone of acceptance of the counter crystal would be relatively free of spleen 


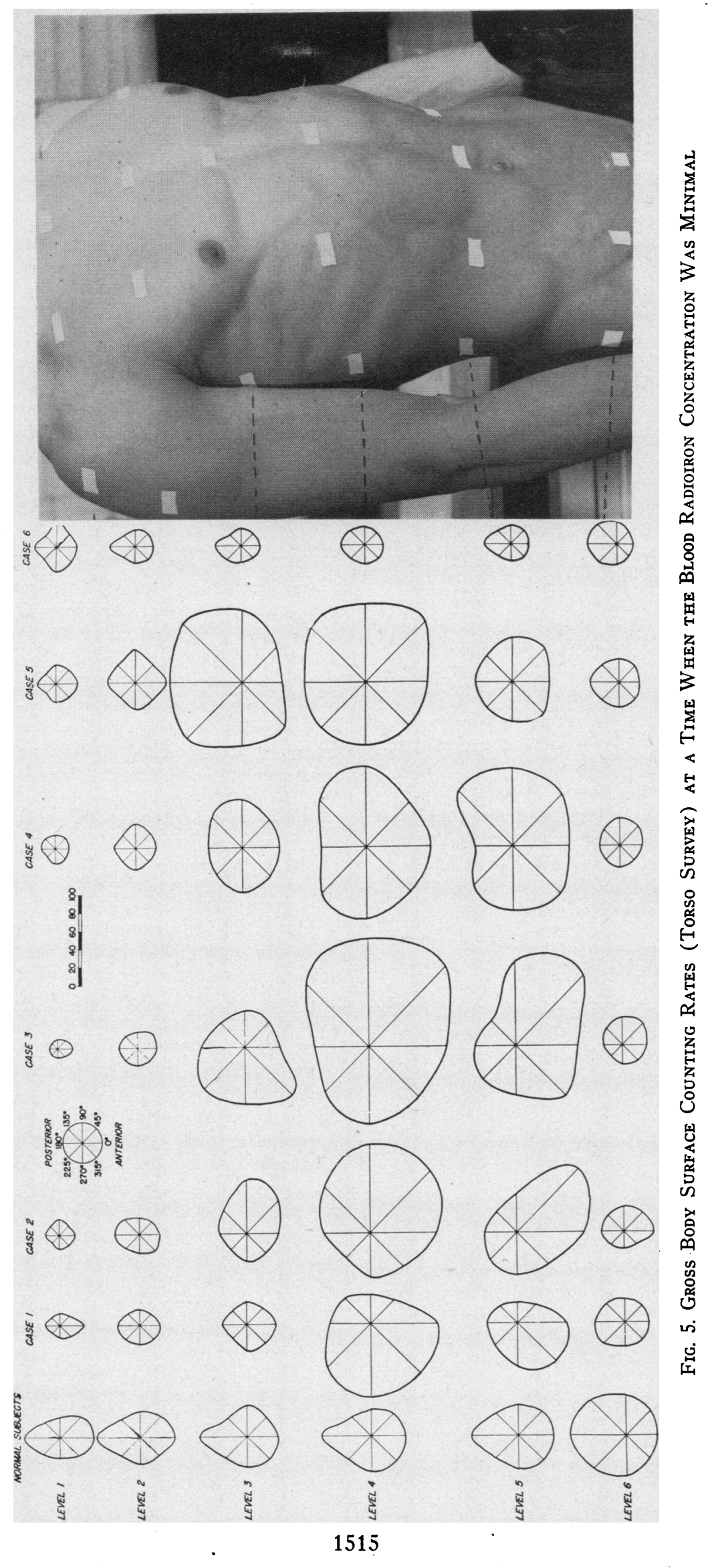


and liver influence, that the sacral position was chosen to determine marrow counting rates as a function of time.

The level used for the sacrum was located by palpation of the posterior spines of the ilium. Counting rates varied considerably with the areas and with time. Usually the range was from 500 to 5,000 counts per minute. Each position was counted long enough so that at least 1,500 counts were recorded-usually more counts than this were recorded.

A typical study was as follows: The various positions to be counted were marked out on the patient's body, and body background counting rates were determined. The injection was made with the patient sitting in the precordial position and an initial count made over the precordium; then the other positions were counted subsequently as rapidly as possible. If the changes were very slow, for example, a plasma $\mathrm{Fe}^{59}$ half-time of five hours, readings were made at approximately hourly intervals; however, if the half-time was short, for example, 10 minutes, positions were counted as rapidly as was possible. As indicated above, these changes with time of the body surface counting rates were recorded on a Leeds and Northrup Speedomax recorder. For more careful analysis these records were usually plotted again on semilogarithmic paper as a rate per microcurie injected. The curves of the marrow, liver, and spleen site counting rates were extrapolated to zero time, and this extrapolated point was taken as the "blood background body surface counting rate" and used in correcting the "gross body surface counting rate" to a count which represented the "tissue body surface counting rate." It was assumed that the entire counting rate at extrapolated zero time represented radioactivity in the blood of the underlying tissue and that the contribution of blood in the tissue to the counting rate was proportional to the amount of the radioiron in the blood at the time (Figure 3 ).

Thus :

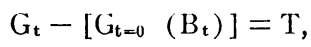

where $G_{t}$ is the gross body surface counting rate at any time; $G_{t=0}$ is the gross body surface counting rate at extrapolated time zero; $\mathrm{B}_{\mathrm{t}}$ is the fraction of $\mathrm{Fe}^{59}$ dose in blood at any time; and $\mathrm{T}$ is the tissue body surface counting rate.

\section{Torso survey at the time of minimal blood tracer con- centration}

When the changes in the body surface counting rates over the three tissue sites were minimal and the blood tracer concentration had declined to a minimum (Figure 3 ), skin surface counting rates were obtained from many points on the torso and, in some instances, from the limbs. In order that there would be uniformity in the selection of points for counting, the following procedure was used:

With a wax pencil the following six body levels were marked on the subject:

1. The suprasternal notch

2. $2 \mathrm{~cm}$. below the manubriosternal juncture

3. Fourth costosternal junction
4. $2 \mathrm{~cm}$. below the xiphisternum

$5.2 \mathrm{~cm}$. above the umbilicus (unless the abdomen was pendulous; then midway between levels 4 and 6)

$6.2 .5 \mathrm{~cm}$. below the anterior superior spine of the ilium.

Eight counting points were used at each of these levels. In each instance the counter receiver was pointed at a curved axis just anterior to the vertebral column. The anterior position was in each instance considered $0^{\circ}$ and the posterior $180^{\circ}$, the left and right midaxillary lines being $90^{\circ}$ and $270^{\circ}$, respectively. All in rivo counting rates were plotted as counts per minute per microcurie injected. The data from the multiple torso examination were plotted on polar coordinates as illustrated in Figure 5. From two to three hours were required for taking the counting rates at these 48 points. During this time there was usually very little change in the combined cell and plasma levels, which often represented less than 0.05 of the administered dose (Figure 3).

\section{Problems associated with in vivo counting}

Among the major problems which have existed in the past is the necessity for large doses of tracer because of the low efficiency of G-M tubes for gamma rays. Usually these doses have exceeded the maximum allowable tissue dose of radiation, at least instantaneously. Now, however, with the use of equipment such as described here, with an efficiency 55 times greater than similar G-M tube equipment, it is possible to restrict the tissue radiation to less than the maximum allowable dose rate. Moreover, the rise in background counting rate is not nearly proportional to the rise in efficiency: in fact, there is an increase in the ratio $\frac{\text { efficiency }}{\text { background counting rate }}$ of 11 compared to similar G-M equipment.4

Ideally the data accrued from an in vivo $\mathrm{Fe}^{5 \theta}$ study should be applicable to the determination of rates of movement of iron from one body compartment or tissue to another. Tobias (8) has pointed out a method whereby rate constants can be calculated from a given set of such data; however, it requires that all of the tracer be accounted for at several times. Any other method depends on estimation and approximation. The difficulty of accounting for all of the tracer at several times by in vivo methods is apparent when some of the variables are considered. In a particular subject, with the counter at a carefully selected site, so as to discriminate against compartments having a different metabolism, many of the variables become constants. For example, with good reproduction of positioning in the same patient, radiation absorption of the intervening tissue becomes constant. Another major variable is the fraction of the tissue or compartment being studied which the counted volume represents. This

4 The efficiency mentioned above for the in vivo counter is 2.9 times that of the crystal used at the beginning of the present studies. For convenience in comparisons between patients, all graphs included in this paper are plotted in counts/minute/microcurie at the old efficiency. 
also can be controlled in a single subject study so that it is a constant. Even though the turnover of tracer iron results in rather discrete separation into compartments, the problem of distinguishing these individual compartments may be great. For example, it is impossible to shield completely a gamma-sensitive device so that the counting rate of the conical tissue volume is not influenced by radiation from other areas. This variable may be eliminated by a "counter" background value taken at each time with the "counter" aperture shielded in the same manner as the "crystal."

Despite these hindrances to approaching the ideal situation in the analysis of iron in vivo tracer data, the uniformity of the data from normal subjects and their comparison to the abnormal affords a description of diagnostic patterns which can be useful in the classification and understanding of erythropoietic function and iron kinetics in normal and pathologic states.

\section{Cases studied}

Normal subjects: five normal male adults, ages 26 to 32 ; one normal female, age 31 ; and one normal male, age 72 ; were studied.

Abnormal cases: These were of varying age and sex and had refractory anemia, hypoplastic marrow (Case 1); polycythemia vera with myelofibrosis (Case 2); myeloid metaplasia with myelofibrosis (Case 3 ) ; chronic myelogenous leukemia and polycythemia vera (Case 4 ) ; chronic myelogenous leukemia (Case 5); multiple myeloma with hemolytic anemia (Case 6); refractory anemia with a hyperplastic marrow (Case 7); secondary polycythemia, polycythemia vera, and chronic lymphatic leukemia.

Synopses of case reports of patients whose $\mathrm{Fe}^{50}$ data are described in most detail are presented.

\section{Case 1, J. M., refractory anemia, hypoplastic marrow}

A 57-year-old married white man, J. M., was referred with the diagnosis of aplastic anemia. History was obtained of an anemia refractory to all the usual methods of therapy and requiring four to five $500 \mathrm{ml}$. transfusions per month since detection in April, 1947.

Physical examination: Physical examinations failed to disclose any notable findings except moderate bronzing of the skin.

\begin{tabular}{|c|c|}
\hline RBC & $2.96-4.02$ million per cu. $\mathrm{mm}$. \\
\hline Hematocrit & $27-35$ \\
\hline Hemoglobin & $8.6-10.9$ gms. per $100 \mathrm{ml}$. \\
\hline Platelets & $140,000-218,000$ per cu. mm. \\
\hline Reticulocytes & $0.1-0.9 \%$ \\
\hline $\begin{array}{l}\text { WBC } \\
\text { Segmented neutrophilic }\end{array}$ & $8,000-13,600$ per cu. mm. \\
\hline granulocytes & $51-81 \%$ \\
\hline Lymphocytes & $20-49 \%$ \\
\hline $\begin{array}{l}\text { Monocytes } \\
\text { Eosinophilic granu- }\end{array}$ & $2-13 \%$ \\
\hline $\begin{array}{l}\text { locytes } \\
\text { Fecal urobilinogen }\end{array}$ & $1-3 \%$ \\
\hline excretion & $75 \mathrm{mg}$. per day. \\
\hline
\end{tabular}

Sternal marrow aspiration on February 20, 1950, showed only $5.8 \%$ of the nucleated cells to be of the erythroid series.

$\mathrm{Fe}^{\mathrm{so}}$ studies were started June 15, 1950.

Course: The course of the disease has been constant. Repeated transfusions have been necessary. Recovery following appendectomy was prolonged and febrile.

Case 2, E. P., polycythemia vera with myelofibrosis

A 41-year-old married woman, E. P., was referred with the diagnosis of polycythemia vera. She had had no radiation therapy.

Physical examination: Physical examination disclosed facial plethora, conjunctival injection, and a spleen so large it almost entered the pelvis.

Laboratory examinations:

RBC

Hematocrit

6.72-8.66 million per cu. $\mathrm{mm}$.

Hemoglobin

Platelets

Reticulocytes

WBC

Segmented neutrophilic granulocytes

Band neutrophilic $\quad 8-19 \%$ granulocytes

Metamyelocytes $\quad 0-6 \%$

Myelocytes 4-15\%

Progranulocytes $\quad 0-2 \%$

Myeloblasts $\quad 0-2 \%$

Eosinophilic granu- $\quad 3-8 \%$ locytes

Basophilic granulo- $\quad 1-13 \%$ cytes

Lymphocytes $\quad 4-15 \%$

Monocytes $\quad 0-2 \%$

Nucleated red cells $\quad 0-5$ per 100 WBC

Uric acid $\quad 5.0 \mathrm{mg} . \%$

Total protein $\quad 8.0$ gms. per $100 \mathrm{ml}$.

Albumin $\quad 4.4$ gms. per $100 \mathrm{ml}$.

Globulin 3.6 gms. per $100 \mathrm{ml}$.

Fecal urobilinogen excretion

$158 \mathrm{mg}$. per 24 hours.

Blood volume, with $\mathrm{P}^{22}$ labeled cells, was $5851 \mathrm{ml}$. (97.5 ml./kg.)

Total red cell volume $\quad 3276 \mathrm{ml}$. (54.6 ml. $/ \mathrm{kg}$.)

Plasma volume $2457 \mathrm{ml}$. $(40.9 \mathrm{ml} . / \mathrm{kg}$.)

Aspiration specimens of the bone marrow were unsatisfactory.

A report on the sternal marrow biopsy was as follows : "The marrow shows a marked, diffuse fibrosis. $\mathrm{Nu}$ merous megakaryocytes are seen. There is a fair number of lymphocytes, eosinophils, fairly well-matured cells of the myeloid series. Diagnosis : Myelofibrosis." No treatment was given and the course is not changed. $\mathrm{Fe}^{\mathrm{s0}}$ studies were started June $28,1950$. 


\section{Case 3, H. E., myelofibrosis with myeloid metaplasia}

A 47-year-old married woman, H. E., was referred with the diagnosis of myelocytic leukemia. She had been given deep roentgen therapy to an enlarged spleen (87 r) on July 28, 1950. On August 4 this dose had been repeated, and on August 11, 1950, $44.4 \mathrm{r}$ were given. The spleen size was reported to be smaller than on August 14 , just before coming to this clinic. At no time was any radiation directed to the marrow:

Physical examination: The spleen was enlarged and the lower border was at the umbilicus.

\section{Laboratory examinations:}

On August 23, 1950, the blood count was:

$\begin{array}{ll}\text { RBC } & 4.68 \text { million per cu. mm. } \\ \text { Hemoglobin } & .10 \text { gms. per } 100 \mathrm{ml} . \\ \text { Platelets } & 130,000 \text { per cu. mm. } \\ \text { WBC } & 13,800 \text { per cu. mm. } \\ \text { Reticulocytes } & 3.5 \% \\ \begin{array}{l}\text { Segmented neutrophilic } \\ \quad \text { granulocytes }\end{array} & 47 \% \\ \text { Band neutrophilic } & \\ \quad \text { granulocytes } & 16 \% \\ \text { Myelocytes } & 8 \% \\ \text { Progranulocytes } & 3 \% \\ \text { Myeloblasts } & 2 \% \\ \text { Lymphocytes } & 23 \%\end{array}$

Sternal marrow aspirations on two occasions contained only peripheral blood. On September 2, 1950, a biopsy of sternal marrow was taken, and the report on the microscopic examination of the sections (decalcified) was: "The sections of the bone show almost complete replacement of the medullary tissue by fibrous tissue, which is rather vascular. A few isolated cells, which appear to have come from the myeloid series, are seen. There is no question about the diagnosis of this marrow. Diagnosis : Myelofibrosis."

Course: From August, 1950, to October, 1950, the blood counts showed a decline to normal values of total white cells. The hemoglobin remained at $10 \mathrm{gms}$. In September the hemoglobin was $8 \mathrm{gms}$. on several determinations, but the total WBC declined from a range of 5,900 6,400 to $3,900-4,200$. Iron studies were started August 31, 1950.

\section{Case 4, P. N., chronic myelogenous leukemia and polycythemia vera}

A 60-year-old married male, P. N., was referred in September, 1946. About two weeks before his first visit, he developed a severe ecchymosis and swelling at the left elbow subsequent to a very minor blow to the arm. He had had no radiation therapy.

Physical examination: The left elbow and forearm were swollen, slightly edematous, and ecchymotic. The spleen was firm and not tender, extending 8-10 cm. below the left costal margin on inspiration. It was estimated to be several times the normal size. The liver was not enlarged.

\section{Laboratory examinations:}

The initial red blood counts were 7.74 to 8.48 million per cu. mm.

The range in values in blood examinations during the course were as follows:

$\begin{array}{ll}\text { RBC } & 3.00-8.42 \\ \text { Hemoglobin } & 8.3-17.7 \text { g } \\ \text { Reticulocytes } & 0.21-10.2 \% \\ \text { Platelets } & 290,000-3 \\ \text { Hematocrit } & 28-63 \\ \text { WBC } & 9,200-42,000 \\ \text { Segmented neutrophilic } & \\ \quad \text { granulocytes } & 58-88 \% \\ \text { Band neutrophilic } & \\ \quad \text { granulocytes } & 3-23 \% \\ \text { Eosinophils } & 1-10 \% \\ \text { Basophils } & 0.4 \% \\ \text { Neutrophilic myelocytes } & 21.6 \% \\ \text { Eosinophilic myelocytes } & 1.0 \% \\ \text { Myeloblasts } & 0.6 \% \\ \text { Lymphocytes } & 0.6 \% \\ \text { Monocytes } & 0.4 \% \\ \text { Nucleated red cells } & 32 \%\end{array}$

Clinical course: With some venesections, $\mathrm{P}^{22}$ and $\mathrm{Y}^{\circ 0}$, he was maintained in good health with a less leukemoid hemogram throughout 1947 and until about mid-1948, when more myelocytes appeared. Later, promyelocytes and myeloblasts appeared, and the RBC had declined gradually so that in late 1948 and early 1949 it varied between 3 and 4 million per cu. mm., with $8 \mathrm{gms}$. of hemoglobin per $100 \mathrm{ml}$. The white counts were not lower and varied from 7,000 to 20,000 per cu. mm. The marrow exhibited a shift to more immature myeloid forms.

During 1949 the liver enlarged and the spleen increased in size, and he was given a transfusion. His blood picture now suggested the late anemic phase sometimes seen in polycythemia vera. The marrow aspiration was unsatisfactory because of dilution with peripheral blood.

He became gradually worse, and his strength and endurance diminished. By May of 1950 he noted some spontaneous ecchymoses similar to those at the onset of his illness two years previously. The spleen and liver increased in size. He had intermittent anorexia and worked less steadily at his job. After each blood transfusion he felt temporarily improved.

Unfortunately the blood volume had not been determined in the polycythemic phase. When it was done, the initial picture had changed to that of an anemia. On September 30, 1949, the blood volume, using $P^{20}$ labeled cells, was $4,453 \mathrm{ml}$. or $64.1 \mathrm{ml} . / \mathrm{kg}$. body weight. The total red cell volume was $1,425 \mathrm{ml}$., or $20.5 \mathrm{ml}$. $/ \mathrm{kg}$. body weight. On February 10, 1950, the blood volume was $5,914 \mathrm{ml}$., or $83.9 \mathrm{ml} . / \mathrm{kg}$., and the total red cell mass was $1,656 \mathrm{ml}$., or $23.5 \mathrm{ml} . / \mathrm{kg}$. Fe $\mathrm{Fe}^{\mathrm{\omega}}$ studies were started May 31, 1950. 


\section{Case 5, E. S., chronic myelogenous leukemia}

A 44-year-old married woman, E. S., was referred with the diagnosis of chronic myelogenous leukemia in September, 1950. An enlarged spleen, an elevated white cell count, and a sternal marrow examination led to the diagnosis of chronic myelogenous leukemia.

Physical examination: The arms showed residual discolorations from old ecchymoses. The spleen was firm, non-tender, and palpable about $2-3 \mathrm{~cm}$. below the costal margin in the left anterior axillary line. No lymph node enlargement was found.

\section{Laboratory examinations:}

The ranges in values in blood examinations were as follows :

$\begin{array}{ll}\text { RBC } & 3.3-3.6 \text { million per cu. mm. } \\ \text { WBC } & 106,000 \text { to } 141,000 \text { per cu. mm. } \\ \text { Hemoglobin } & 7.4-8.5 \text { gms. per } 100 \mathrm{ml} . \\ \text { Platelets } & 215,000-420,000 \text { per cu. } \mathrm{mm} .\end{array}$

The blood volume studies by the $\mathrm{P}^{2 s}$ tagged cell method were recorded as follows:

$\begin{array}{lr}\text { Blood volume } & 4,387 \mathrm{ml} \text {. or } 72.5 \mathrm{ml} . / \mathrm{kg} . \\ \text { Total red cell volume } & 1,163 \mathrm{ml} \text {. or } 19.2 \mathrm{ml} . / \mathrm{kg} . \\ \text { Plasma volume } & 2,895 \mathrm{ml} \text {. or } 47.9 \mathrm{ml} . / \mathrm{kg} .\end{array}$

Course: She returned to her physician with arrangements for small doses of radioactive phosphorus. $\mathrm{Fe}^{*}$ studies were started September 12, 1950, prior to any radiation therapy.

\section{Case 6, C. H., multiple myeloma}

A 65-year-old married male, C. H., was referred January 9, 1950. About five months before, a hard swelling arose just above the left ankle. A biopsy was done, and the microscopic examination as well as roentgenograms of bones disclosed multiple myeloma. He had lost 15 to 20 pounds in weight during the past year. At the time he was first examined here, he complained: of an unremitting pain in the right elbow.

Physical examination: The skin had a slight icteric tint. He was thin and the muscles were flabby. The spleen was palpated $1-2 \mathrm{~cm}$. beneath the costal margin, and a larger than usual area of splenic dullness found. Bone tenderness was found over the distal end of the right humerus and the left ulna.

\section{Laboratory examinations:}

Prior to any therapy the range in RBC per cu. $\mathrm{mm}$. was 2.97 to 4.00 million.

$\begin{array}{ll}\text { Hemoglobin } & 8.4-10.9 \text { gms. per } 100 \mathrm{ml} . \\ \text { WBC } & 5,400-10,400 \\ \text { Reticulocytes } & 0.6-9.7 \% \\ \text { Hematocrit } & 19-28\end{array}$

The differential white count was within the normal range. On January 9, 1950, the aspirated sternal marrow was found to have $43 \%$ nucleated red cells and $5.2 \%$ plasma cells. On September 6, 1950, the sternal marrow contained $61 \%$ nucleated red cells and $0.8 \%$ plasma cells. $\mathrm{Fe}^{\infty}$ studies were started November 16, 1950.

Only once was the test for Bence-Jones protein in the urine positive. A month later and on many subsequent tests none has been detected.

Total protein was 4.92 , albumin 2.92 , globulin 2.00 gms. per $100 \mathrm{ml}$. of plasma on January 11, 1950.
Icteric index
25 on July 24, 1950, and August 8, 1950
Serum bilirubin
Fecal urobilinogen
excretion
$0.4 \mathrm{mg}$. per $100 \mathrm{ml}$. blood
$860 \mathrm{mg}$. per 24 hours

Course: Treatment with urethane and $\mathrm{P}^{23}$ apparently did not alter the course. He has not required transfusions.

\section{Case $7, C . H$., refractory anemia}

This 72-year-old male was first discovered to have an anemia in October, 1949.

Physical examination: The liver edge was $4-6 \mathrm{~cm}$. inferior to the costal margin at the end of deep inspiration. The spleen was enlarged on deep inspiration, extending 4 cm. inferior to costal margin in the mid-axillary line.

Laboratory examinations:

The blood data showed the following ranges:
RBC

Hematocrit

Hemoglobin

Platelets

Reticulocytes

Nucleated red cells

WBC

Segmented neutrophilic granulocytes

Band neutrophilic granulocytes

Metamyelocytes

Progranulocytes

Myeloblasts

Eosinophilic granulocytes

Basophilic granulocytes

Fecal urobilinogen excretion

Coombs test
1.80-3.94 million per cu. $\mathrm{mm}$. 19-36

7.5-12.1 gms. per $100 \mathrm{ml}$. $260,000-500,000$ per cu. mm. $0.1-1.8 \%$ 0-1 per $100 \mathrm{WBC}$ $6,600-13,000$ per cu. mm.

$18-66 \%$

$1-30 \%$

$0-1 \%$

$0 \%$

$0 \%$

$0-15 \%$

$0-6 \%$

154-299 mg. per day negative
On February 9, 1950, the pathologist's report of a marrow biopsy was as follows: "The bone marrow shows a rather moderate increase of large and nucleated red cells. This slide shows essentially the same pattern that we saw in the previous bone marrow biopsy. Diagnosis : Hyperplasia of bone marrow."

Course: The course has not been altered except for a lower requirement of blood by transfusion following splenectomy. He has received all of the various vitamins and liver concentrates as well as crude liver parenteral injections and raw liver by mouth. $\mathrm{Fe}^{\infty}$ studies started June 21, 1950, several months before the splenectomy. 


\section{RESULTS AND DISCUSSION}

The plan of this part of the paper is to present the data with the discussion in the chronological manner in which the data were collected. This form allows the introductory presentation of the results of the most simple technique and progression to the more complex. The results and discussion are organized in three general sections. Section I includes the raw data of gross body surface counting rates as a function of time after a single intravenous injection of $\mathrm{Fe}^{59}$ during the first day of each study. It illustrates what may be learned by this technique during a relatively short study with little equipment and effort. Section II concerns a more extensive and laborious examination of the patient, the purpose of which is to learn the general location in the body of the tracer once it has left the blood stream. Section III gives data from studies which cover a two-week period. The data of the latter section are treated in a special manner by which the gross body surface counting rates are corrected for the contribution of radioactivity from plasma or red cells, and thus these data represent more nearly the tissue body surface counting rates.

\section{The gross body surface counting rates over sacrum, liver, spleen and precordium dur- ing the first day after injection of $F e^{59}$}

These data are illustrated in Figure 4, refractory anemia with hypoplastic marrow (Case 1); polycythemia vera with myelofibrosis (Case 2); myeloid metaplasia with myelofibrosis (Case 3 ); chronic myelogenous leukemia (Case 5); and normal male adult.

Deviations from the normal gross body surface counting rates may be evident in some cases during the first 15 minutes after the injection of the tracer iron. As the four positions are "counted," excessively rapid disappearance of the tracer from the blood or an unusually rapid rise in counting rate over marrow, spleen, or liver may be seen directly on the moving recorder paper. A rapid and excessive rise in counting rate over liver or spleen is accompanied by a partial or complete failure of the marrow counting rate to rise (Figure 4). An estimate of the ability of the bone marrow and other tissues to accumulate radioiron is possible in the first few hours of a study. In the normal subject the sacral position was the only position showing a rising counting rate during the first eight hours. The counting rate over liver was practically constant with time, while that over the precordium and spleen fell to a near plateau level relatively soon. Since intravascular mixing time is short compared to the usual blood removal time of radioiron, it is reasonable to assume that gross body surface counting rates over a tissue during the first few minutes represent the radioactivity which is contained in the perfusing plasma. Similarly, in ten to 14 days, $80-100 \%$ of the radioactivity is again contained in blood but at this time in the red cells. Thus, in these very early periods and in the late periods, nearly all of the injected dose is in the blood, first in the plasma and later in the red cells. The contribution of blood radioactivity to the gross body surface counting rates is nearly the same at these two times except possibly in such tissues as may have different hematocrits. Thus a gross body surface counting rate constant with time during a period when the radioactivity in blood is known to be decreasing indicates that the tissue is accumulating radioactivity. This is the situation which is usually found over the liver, in contrast to the spleen where the counting rate falls as a function of time.

In contrast to the sacral counting rates of normal individuals, which rise with time, nearly constant sacral counting rates are seen in the cases represented in Figure 4. Case 3 (Figure 4), myelofibrosis with myeloid metaplasia, shows a decrease in sacral counting rate with time. This is the type of curve which might be expected in the absence of marrow erythropoiesis. Reference to the case descriptions shows the coincidence of a low counting rate over sacrum with the marrow biopsy findings of hypoplasia or aplasia of the erythroid series, or of fibrosis.

The extraordinarily high rise of counting rates occurring over spleen, as demonstrated in Figure 4 (Case 2, polycythemia vera with myelofibrosis; and Case 3, myelofibrosis with myeloid metaplasia), was not necessarily expected although there was splenomegaly in both cases. This similarity in the two cases is in contrast to the finding of polycythemia in the one and anemia in the other. The spleen counting rate of Case 5 (myelogenous leukemia), Figure 4, is intermediate and represents some ability of the spleen to accumulate iron. That 
splenomegaly is not always associated with splenic removal of radioiron from plasma was demonstrated in a case having chronic lymphatic leukemia whose spleen filled half the abdominal cavity. This patient showed a spleen curve which was very similar to the normal, with no evidence of direct clearance of radioiron from plasma.

Experimentally a spleen $\mathrm{Fe}^{59}$ curve resembling that of the typical $\mathrm{Fe}^{59}$ marrow curve has been demonstrated in rats receiving total body X-radiation with their spleens protected. Direct splenic removal of radioiron from plasma was shown to be associated with the subsequent appearance of tagged red cells (9).

Figure 4 (Case 1, refractory anemia with hypoplastic marrow) demonstrates the situation wherein the usual marrow ability to deplete the plasma of tracer is replaced by a very slow removal by liver.

\section{The torso survey for $F e^{59}$ at a time when the blood level of radioiron is minimal (Illus- trated by Figure 5)}

The desirability of knowing more accurately the tissue distribution of tracer when it was nearly absent from blood led to the system of body profile counting rate and its associated polar plot, described earlier in this paper in METHODS under "Torso Survey at the Time of Minimal Blood Tracer Concentration." The blood tracer concentration in each case was ascertained to be minimal by reference to data, as shown in Figure 3. The averaged data of five normal male adults are graphed in Figure 5. The shape of the uppermost levels with the posterior projection indicates the association of vertebrae with the iron isotope. The subsequent finding of the tracer incorporated in the red cells is an indication of a normally functioning marrow.

In the third and fourth levels of the plots of the normal cases the shape is similar. There is a slight asymmetry with a right preponderance, which probably indicates the normal liver iron turnover. That the third and fourth levels are not more asymmetrical shows that the major stream of iron from plasma is normally to bone marrow. Finally, the larger area of the lowermost level shows that this region in the 23-33 year age group probably contains a considerable portion of the red marrow of the body. That this distribution may not hold for all age groups is indicated by the finding of a contracted sixth level in a 72-year-old normal male.

In the early studies it was thought worthwhile to explore the head and the extremities as well as the torso; however, the counting rates of the skull and the extremities were usually very low. It was noted that excessive erythroid marrow hyperplasia was associated with a more diffuse skeletal distribution of radioiron, resulting in contracted polar plots of the torso (Figure 5, Case 6, multiple myeloma with hemolytic anemia).

The grotesque figures (Figure 5) from Case 1, refractory anemia with hypoplastic marrow; Case 2 , polycythemia vera with myelofibrosis; Case 3 , myeloid metaplasia with myelofibrosis; Case 4, chronic myelogenous leukemia following polycythemia vera; and Case 5, chronic myelogenous leukemia, exemplify the aberrant iron kinetics which are associated with certain abnormalities in hematopoiesis.

Case 1, Figure 5 (refractory anemia with hypoplastic marrow, the same patient as shown in Figure 4) demonstrates the relative failure of tracer to accumulate in marrow areas and negligibly in spleen. The fraction of tracer appearing in red cells in this case never exceeded 0.12 of the injected dose, and the liver counting rate increased slowly with time and never decreased.

Case 2, Figure 5 (polycythemia vera with myelofibrosis, the same as in Figure 4) shows the major accumulation of tracer in the splenic region with very little in the normal marrow areas. That this abnormal location of iron was associated with red cell production in the spleen was indicated by the high fraction of the tracer dose which appeared in red cells and is confirmed by the polycythemia and the morphologic finding of myelofibrosis.

Case 3, Figure 5 (myeloid metaplasia with myelofibrosis) shows a large portion of the tracer in spleen and also a significant amount in liver. A bone marrow biopsy from this patient was reported as showing almost complete replacement of the normal medullary tissue by fibrous tissue. The maximum fraction of the tracer which was present in the erythrocytes at any one time during the first two weeks of study was 0.6. The concomitant drop in counting rates over spleen and liver with a rise in erythrocyte concentration of tracer indicated the possibility that the liver as well as the 
spleen was involved in erythropoiesis. The asymmetry of the polar plot with a left preponderance, indicated that the spleen was the more important for this purpose. This pattern differs from myelocytic leukemia (Case 5, Figure 5) in which evidence of hepatic and splenic metaplasia as well as some marrow function exists.

Case 4, Figure 5 (chronic myelogenous leukemia and polycythemia vera) shows a lack of the expected gross body surface counting rates in the normal marrow locations. Instead, the tracer rapidly accumulated almost equally between the liver and the spleen. The subsequent appearance of approximately 0.4 of the tracer dose in red cells, with a concomitant fall in counting rate over the spleen and a constant counting rate over liver, showed erythroid metaplasia of the spleen and suggested storage function of the liver. Repeated marrow aspirations during the course of the illness indicated a diminishing marrow cellularity.

The previous discussion of results is illustrative of the usefulness of the application of in vivo $\mathrm{Fe}^{59}$ methods in following the immediate movement of the tracer from plasma to the various tissue sites.

\section{The tissue body surface counting rates over sacrum, liver, and spleen during the first two weeks after the injection of $F e^{59}$ (Illus- trated by Figures 6-8)}

A more comprehensive insight is gained of the functional significance of the particular tissue distribution if plasma and red cell sampling as well

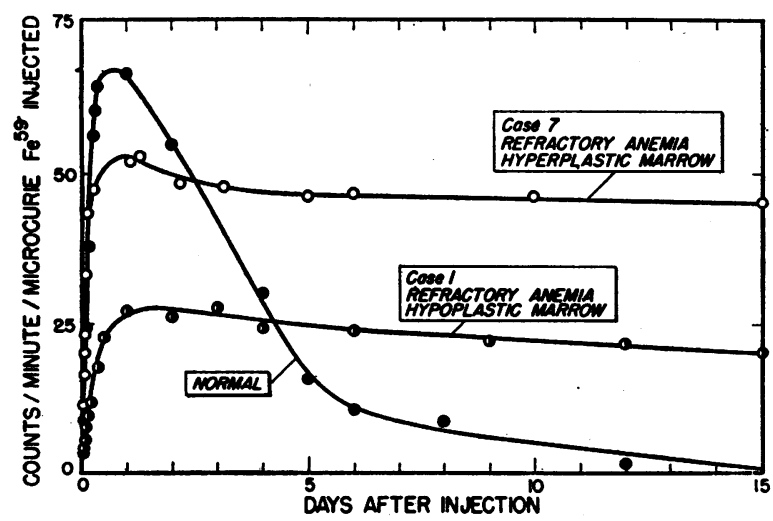

Fig. 6. Tissue Body Surface Counting Rates over Sacrum as a Function of Time after a Single IntravENOUS INJECTION OF FE

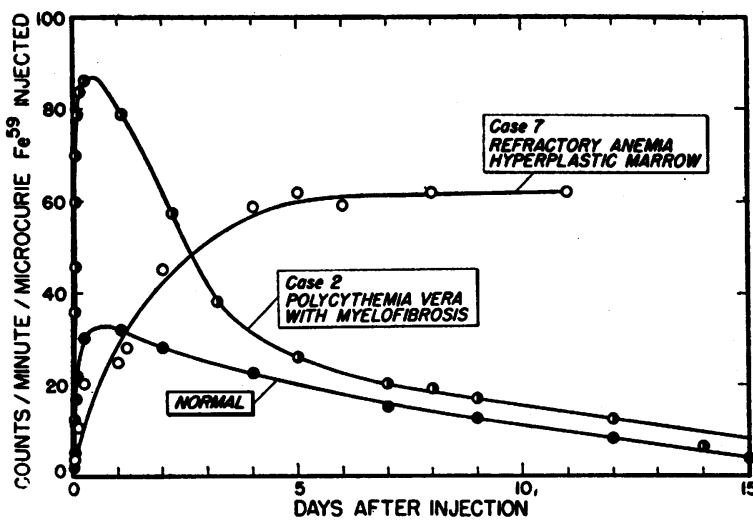

Fig. 7. Tissue Body Surface Counting Rates over Spleen as a Function of Time after a Single IntraVENOUS INJECTION OF FE

as body surface counting rates are continued for a longer period of time. The data presented in Figures $6-8$ are the gross body surface counting rates per microcurie injected minus the counting rate contributed by blood. The curve illustrated in Figure 3 was used for this correction (see METHODS).

Figure 6 shows such data from the representative marrow site. Included are three cases : a normal male adult, a patient with refractory anemia, hyperplastic marrow (Case 7), and a patient with refractory anemia, hypoplastic marrow (Case 1 ). The curve of the representative marrow site from the normal subject, in its time concentration relationship, resembles very closely similar data which have been obtained by serial animal tissue sampling $(9,10)$. Comparison of the data of the

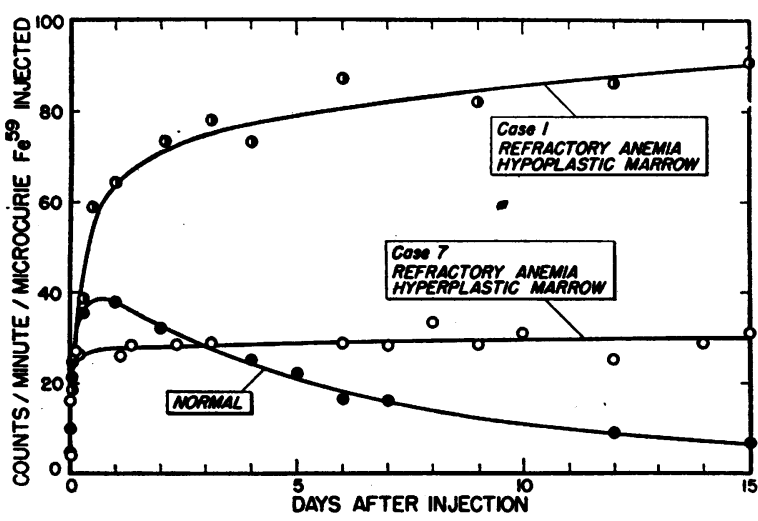

Fig. 8. Tissue Body Surface Counting Rates over Liver as a Function of Time after a Single IntraVENOUS INJECTION OF FE 
normal subject of Figure 6 with Figure 3 shows the concomitant rise in red cell concentration of tracer and the fall in marrow counting rate. It is not surprising that the counting rate over the marrow site of Case 7 (refractory anemia, hyperplastic marrow), Figure 6 , rose to a fairly high level, almost normal. That it did not rise as high as the normal is possibly associated with the greater dispersion of functioning marrow. Corroborative evidence was the finding of slightly contracted polar plots, as with Case 6, Figure 5. Also, it was expected that the marrow of the hypoplastic anemia patient (Case 1 ) would accumulate very little $\mathrm{Fe}^{59}$. The surprising point was the failure of the subnormal counting rates of Cases 1 and 7, Figure 6, to fall. This phenomenon need not be considered a static one; i.e., it is not necessarily indicative of iron accumulation in the marrow without discharge. Instead, it may indeed indicate a very rapid turnover through marrow with a high equilibrium level. Indirect evidence that the latter is probably true is gained from other considerations of these and other cases. For example, such findings are usually associated with a "secondary" rise in spleen counting rates, as illustrated by Case 7 in Figure 7 (refractory anemia with hyperplastic marrow). This rise is secondary in that it does not occur as the iron is initially cleared from the plasma but only subsequent to its appearance in marrow. Case 6, having multiple myeloma and a severe anemia, had data of this nature and had additional evidence of extraordinary erythropoietic hyperfunction in that the marrow showed $65 \%$ of the cells to be of the erythroid series and the stool urobilinogen excretion to be greater than $800 \mathrm{mg}$. per day. On the other hand, there have been observations showing that patients such as Case 7 may have hemosiderin granules in their marrow. Thus, a possible reason for the marrow counting rate not being near zero two weeks after injection in Case 1 may be related to non-erythrogenic medullary iron function (11).

From Figure 7 a comparison may be made of tissue body surface counting rates over the spleen in a normal subject and in two patients. The spleen curve of Case 2 (polycythemia vera with myelofibrosis) is remarkably similar in time concentration relationship to the normal marrow curve (Figure 6). The drop in counting rate over the spleen in Case 2 was associated with a rise in the erythrocyte tracer concentration to near normal levels. This type of spleen curve has been called erythrogenic in that it rises as the concentration of the injected radioiron in plasma falls, and falls as the erythrocyte concentration of tracer rises. Another type of curve associated with spleen, distinctly different from the primary type, is illustrated by the data of Case 7 (refractory anemia with hyperplastic marrow), Figure 7. In this instance a great rise in counting rate over spleen occurs following or simultaneously with a fall in counting rate over sacrum and concomitantly with a subnormal rise in erythrocyte concentration of radioiron. This type of splenic radioiron curve has been called erythroclastic. Despite the fact that these tissue body surface counting rates over spleen are corrected for the contribution of counting rate by radioisotope in the circulating blood (see METHODS), they are higher at three to 10 days than they are when all of the isotope is in the plasma; i.e., just after injection.

Convincing evidence that the erythrogenic spleen curve, as seen in Case 2 (polycythemia vera with myelofibrosis), is the result of splenic erythroid metaplasia are the facts that this patient (see Case 2 report) had myelofibrosis and polycythemia (red cell mass, $54.6 \mathrm{ml} . / \mathrm{kg}$.), and that nearly all of the tracer was in red cells within 10 days after the dose was given. The polar plots (Figure 5, Case 2) suggest the presence of myelofibrosis throughout the areas usually containing normal marrow.

Corroborative data showing that the erythroclastic spleen curve is associated with excessive cell destruction are given in the case reports of Cases 6 and 7, which had this type of spleen curve. The pertinent findings are anemia, marrow hyperplasia, reticulocytosis, high iron turnover rates, near normal uptakes of radioiron in marrow, high stool urobilinogen excretion, and a high icteric index. The extirpated spleen of Case 7 (refractory anemia with hyperplastic marrow) showed no evidence of erythroid metaplasia but did show hyperplasia of the reticulum. There was no evidence of excessive deposits of iron pigments in the spleen. It weighed $585 \mathrm{gms}$. The routine findings in these two individuals (Cases 6 and 7) which are ordinarily associated with the diagnosis of hemolytic anemia are different in that they are 
clear-cut and definite in Case 6 but questionable or absent in Case 7 . In contrast, plasma iron turnover rates are increased in both cases; and both cases show the erythroclastic curve.

We believe this affords a method for distinguishing some anemias of abnormal formation from those of abnormal destruction. The findings of a more rapid than normal iron turnover, erythroclastic curve, the absence of excessive urobilinogen excretion, and the absence of high serum bilirubin and reticulocytes go together to indicate an abnormality or failure in the formation of hemoglobin and the rapid destruction of abnormal cells. This type of case could well be called an anemia of abnormal hemoglobin formation with resulting short cell life (12).

The second type of case in which the usual findings indicating abnormally rapid destruction and formation of erythrocytes are present with excessive iron turnover and an erythroclastic spleen curve could be considered as having an abnormally rapid destruction of red cells, not the result of an inherent abnormality in hemoglobin formation, but existing independently of erythrogenesis except for the stimulation it affords.

In Figure 8 is presented the tissue body surface counting rate over liver from a normal subject and from two patients with refractory anemia (Case 1 and Case 7). The curve from the patient with a hypoplastic marrow (Case 1) differs from the normal in that it rises beyond the expected value and after 12 to 14 hours continues to rise, albeit at a slower rate, while that of the normal tends to decrease slowly. The patient having the hyperplastic marrow (Case 7) shows a failure of the counting rate over liver to reach the normal value and then tends to increase slowly.

Case 1, with a hypoplastic marrow, illustrates the failure of the major pathway of iron from plasma to marrow to function and the substitute of the liver as the major pathway. The gradual slow gain in counting rate over liver is in accordance with the well-known function of the liver to effect net gains in iron when there is a failure in red cell formation or when extra iron is introduced into the body. The patient having the hyperplastic marrow (Case 7) demonstrates that the major exit of the iron from the plasma may continue to be marrow, even in the presence of severe anemia and abnormalities in medullary morphology. In fact, the diversion of iron to this type of marrow is possibly greater than normal and accounts for the failure of counting rate over the liver to rise initially to the normal value. The rising counting rates over liver in the later days of the study indicate net gains of iron. Measurements over this patient's liver were continued for 70 days, at which time the counting rate over liver was higher than over any other area.

\section{SUMMARY}

The kinetics of intravenously injected $\mathrm{Fe}^{59}$ Globulin IV-7 in tracer doses were observed by external scintillation counting over marrow, liver, and spleen as well as by in vitro analysis of plasma and erythrocyte radioactivity. Thirty patients and seven normal subjects were studied.

The quantity of tracer in the plasma and red cells was plotted as a function of time; and the relative counting rates representing the other three compartments (marrow, liver and spleen), free from the counting rate contributed by blood, were plotted in a similar manner. In order to assess the significance of a tissue counting rate, a survey of the torso was made when the combined plasma and erythrocyte level was minimal. Polar coordinate plots of the relative counting rates of six cross-sectional torso levels indicated the relation of the spleen, liver, or marrow counting rates to those over the remainder of the body.

The kinetics were remarkably uniform in young male adults. The tissue of major importance in depleting the plasma of the tracer was the bone marrow. The time required for the plasma depletion was quite uniform. This major initial transient accumulator, the bone marrow, was observed simultaneously to discharge the tracer as it appeared in the circulating erythrocytes. A minor initial transient accumulation occurred in the liver. This was seen to feed back into the major pathway: plasma, to marrow, to red cells.

In the patients, abnormalities in the initial direction or destination as well as in velocity were observed.

In subjects having known marrow hyperplasia without splenic or hepatic abnormality (for example, secondary polycythemia), the velocity from plasma to marrow was increased. The marrow volume apparently included the extremities as was 
evidenced by the lesser area of the normally shaped torso polar plots.

When the major initial transient accumulator was spleen, there was always an increased velocity. Such patients showed microscopic evidence of lack of erythrogenic tissue in the bone marrow. If the initial transient major accumulation was divided among liver, marrow and spleen or liver and spleen alone, the velocity was also great.

The presence of a large spleen was found not to be indicative of a particular type of iron kinetics. Two types of splenic curves were observed which are thought to represent erythrogenic and erythroclastic phenomena. The conditions for the erythrogenic spleen curve were: (1) The spleen showed the ability to accumulate a greater than normal amount of radioiron as the high initial plasma concentration fell; and (2) The spleen subsequently discharged this excess of radioiron as the red cell concentration of radioiron rose. The condition with the erythroclastic spleen curve was: The spleen showed the ability to accumulate an abnormally great amount of radioiron concomitantly with a fall in marrow radioiron and a rise in red cell concentration. "Erythroclastic" is not used to indicate that the primary abnormality is necessarily splenic but only to indicate excessive cell destruction.

Two cases are presented having erythroclastic spleen curves, one of which had findings indicating that the spleen was primarily at fault, and the other having evidence of abnormal hemoglobin and cell formation.

The liver was never observed to be the major remover of iron from the plasma to discharge it into cells; however, it, with the spleen, might share in various portions the delivering of tracer to the second major compartment, the red cells.

A subnormal velocity was associated with the exclusive hepatic removal of tracer from plasma. For example, 48 hours might be required to deplete the plasma of tracer to a level that would be achieved in one or two hours in a case where the spleen or bone marrow was the receptacle. However, exclusive hepatic removal was not always associated with plasma iron turnover rates which were markedly below normal. When the liver was the major primary accumulator, it continued to maintain high levels for many days and no sec- ondary wave of high counting rates appeared over any of the other four compartments studied.

Failure of the normal second major compartment, the circulating erythrocytes, to exhibit accumulation of $\mathrm{Fe}^{59}$, was associated with all variations in the preceding kinetics; that is, plasma to spleen, plasma to liver, or plasma to bone marrow. An interesting partial failure of the erythrocytes to accumulate tracer even though the marrow depleted the plasma or $\mathrm{Fe}^{58}$ occurred with the appearance of a third receptable, the spleen. In one of these patients who presented the usual findings of excessive hemoglobin production and destruction, the velocity of $\mathrm{Fe}^{59}$ from plasma to marrow was great, and there was no other tissue collecting the tracer. The marrow appeared to empty itself only partially of the tracer; moreover, the erythrocytes did not accumulate their normal portion, and simultaneously splenic counting rates rose over a two to four day period. Finally, an abnormal equilibrium was established in which the levels in spleen and marrow were very high, while that of the erythrocytes was unusually low.

It is concluded that in vivo studies with $\mathrm{Fe}^{50}$ are of value in the study and diagnosis of various hematopoietic disorders. These studies are also a useful adjunct in the guidance of the clinician in therapy.

\section{ACKNOWLEDGMENTS}

The authors wish to thank their colleagues, Professor Cornelius A. Tobias and Mr. Hal Anger, who designed and built the scintillation counting equipment which made these studies possible.

\section{REFERENCES}

1. Huff, R. L., Hennessy, T. G., Austin, R. E., Garcia, J. F., Roberts, B. M., and Lawrence, J. H., Plasma and red cell iron turnover in normal subjects and in patients having various hematopoietic disorders. J. Clin. Invest., 1950, 29, 1041.

2. Anger, H. O., A new counting rate recorder. A. E. C. Report, UCRL 885, August 30, 1950.

3. Anger, H. O., Scintillation counters for the measurement of radioactive samples. A. E. C. Report, UCRL 886, August 30, 1950.

4. Keim, C. P., Savage, H. W., and Weaver, B., Electromagnetic enrichment of $\mathrm{Fe}^{\mathrm{ss}}$ content and concurrent impoverishment of $\mathrm{Fe}^{\mathrm{st}}$ content in iron. Science, 1950, 112, 47.

5. Surgenor, D. M., Koechlin, B. A., and Strong, L. E., Chemical, clinical, and immunological studies 
on the products of human plasma fractionation. XXXVII. The metal-combining globulin of human plasma. J. Clin. Invest., 1949, 28, 73.

6. Kitzes, G., Elvehjem, C. A., and Schuette, H. A., The determination of blood plasma iron. J. Biol. Chem., 1944, 155, 653.

7. Mechanik, W., Untersuchunger ueber das Gewicht des Knochenmarkes des Menschen. Ztschr. f. Anat., 1926, 79, 59.

8. Tobias, C. A., Determination of the rate of biochemical reactions. A. E. C. Report, UCRL 157, Pt. 2, June 1948.

9. Huff, R. L., Bethard, W. F., Garcia, J. R., Roberts, B. M., Jacobson, L. O., and Lawrence, J. H., Tracer iron distribution studies in irradiated rats with lead-shielded spleens. J. Lab. \& Clin. Med., $1950,36,40$.

10. Copp, D. H., and Greenberg, D. M., A tracer study of iron metabolism with radioactive iron. I. Methods : Absorption and excretion of iron. J. Biol. Chem., 1946, 164, 377.

11. Rath, C. E., and Finch, C. A., Sternal marrow hemosiderin. A method for the determination of available iron stores in man. J. Lab. \& Clin. Med., 1948, 33, 81.

12. Mills, H., Huff, R. L., Krupp, M. A., and Garcia, J. F., Hemolytic anemia secondary to a familial (hereditary) defect in hemoglobin synthesis: report of a case with radioiron studies. Arch. Int. Med., 1950, 86, 711. 